\title{
Erratum
}

\section{Resveratrol enhances GLUT-4 translocation to the caveolar lipid raft fractions through AMPK/Akt/eNOS signalling pathway in diabetic myocardium}

\author{
S. Varma Penumathsa ${ }^{\text {a, c }}$, M. Thirunavukkarasu ${ }^{\text {a }}$, L. Zhan ${ }^{\text {a }}$, G. Maulik $^{\text {b }}$, \\ V. P. Menon ${ }^{c}$, D. Bagchi ${ }^{d}$, N. Maulik ${ }^{a}$ \\ ${ }^{a}$ Molecular Cardiology and Angiogenesis Laboratory, Department of Surgery, \\ University of Connecticut Health Center, Farmington, CT, USA \\ ${ }^{b}$ Department of Thoracic Surgery, Harvard Medical School, Boston, MA, USA \\ ${ }^{c}$ Department of Biochemistry and Biotechnology, Annamalai University, TN, India \\ ${ }^{d}$ Interhealth Research Center, Benicia, CA, USA
}

In [1], the authors note that the Glut-4 blot in Figure 4B corresponding to the conditions 'diabetes', were incorrect. The corrected figure panel appears below. This error does not affect the conclusion of the study.

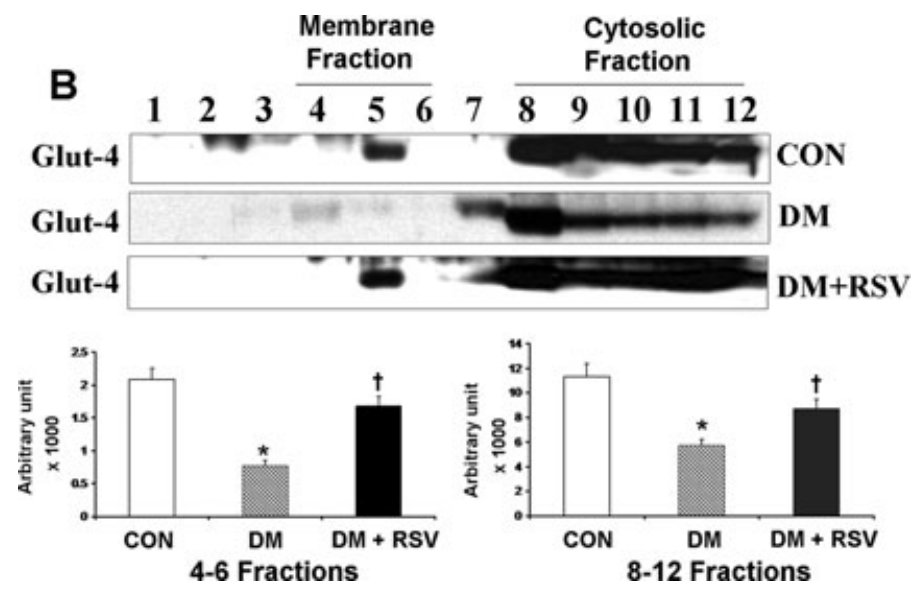

\section{Reference}

[1] Penumathsa SV, Thirunavukkarasu M, Zhan L, et al. Resveratrol enhances Glut-4 translocation to the caveolar lipid fractions through AMPK/AKT/eNOS signaling pathway in diabetic myocardium. J Cell Mol Med. 2008; 12: 2350-61. 